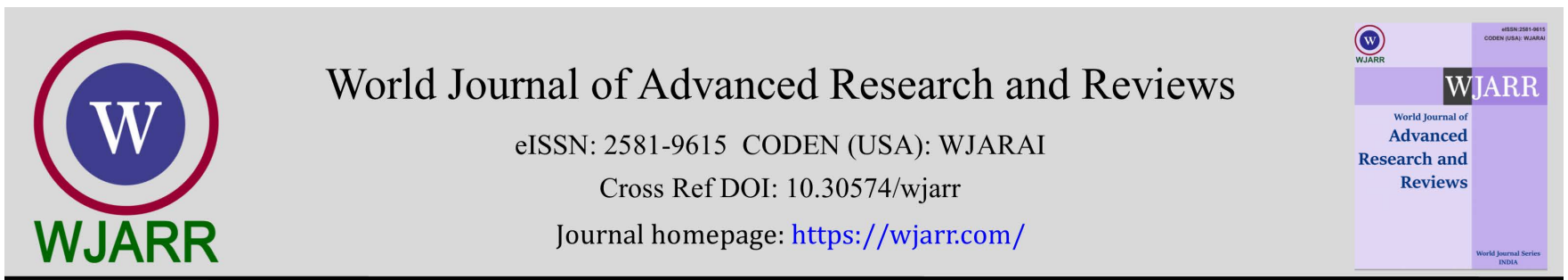

(RESEARCH ARTICLE)

Check for updates

\title{
Nigeria's multidimensional poverty analysis: A subgroup and dimensional breakdown
}

\author{
Emeka Eze and Justin C. Alugbuo* \\ Department of Economics, College of Management Sciences (COLMAS), Michael Okpara University of Agriculture, Umudike, \\ Umuahia, Abia State, Nigeria.
}

World Journal of Advanced Research and Reviews, 2021, 11(02), 219-226

Publication history: Received on 12 July 2021; revised on 15 August 2021; accepted on 17 August 2021

Article DOI: https://doi.org/10.30574/wjarr.2021.11.2.0383

\begin{abstract}
This study is an attempt to analyze the nature of multidimensional poverty in Nigeria in the light of recent data. The study used data from the Nigerian standard of living and measurement survey (LSMS) 2018/2019 to estimate the overall MPI for Nigeria, which included six indices of deprivation from four dimensions: consumption, education, energy, and housing. The study also performed a decomposition of multidimensional poverty across Nigerian regions, as well as a dimensional breakdown of multidimensional poverty across Nigeria and across regions. According to the study, Nigeria's multidimensional poverty index is 0.34 , with a headcount ratio of 0.64 when the deprivation cutoff is 1 , implying that roughly 64 percent of Nigerians are poor in at least one of the four areas studied. The North West, North East, and North Central regions, on the other hand, account for the majority of Nigeria's multidimensional poverty, accounting for more than $70 \%$ of the country's total multidimensional poverty. The South West has the lowest poverty rate, followed by the South South and the South East. Deprivations in Education, Energy, Consumption, and Housing, according to the report, are the most significant contributors to MPI. The study recommends that policies aimed at reducing poverty must take into account the distribution of multidimensional poverty in Nigeria so as to be able to get to the targeted audience. Secondly, there is a need to improve investment in Education and Energy so as to reduce overall multidimensional poverty in Nigeria.
\end{abstract}

Keywords: Multidimensional Poverty; Nigeria; Poverty; Standard of Living

\section{Introduction}

\subsection{Background to the study and Statement of the Problem}

Since the 1970s, economists have increasingly acknowledged that poverty is multidimensional [1]; [2], involving interconnected variables that are linked and complimentary [1], [2]. Increased poverty metrics have been devised to illustrate the intricate interrelationships between monetary and nonmonetary poverty as a result of this new understanding of poverty's complexity. Nearly everyone acknowledged by the turn of the millennium that poverty is interconnected and that monetary poverty has complementary ties with other forms of nonmonetary deprivation. The adoption of the Millennium Development Goals and, later, the Sustainable Development Goals between 2000 and 2015 was a testament to this understanding, demonstrating that policies aimed at eradicating poverty holistically must begin with an understanding of poverty's multidimensional nature, particularly the interconnections between various forms of deprivation that limit human development.

\footnotetext{
* Corresponding author: Justin C Alugbuo; Email: jc.alugbuo@mouau.edu.ng

Department of Economics, College of Management Sciences (COLMAS), Michael Okpara University of Agriculture, Umudike, Umuahia, Abia State, Nigeria. 
One of the advantages of multidimensional poverty studies over unidimensional poverty studies is that the former's definition of poverty is broader, allowing a higher number of destitute people to be included. When we consider that, while the link between monetary poverty and other deprivations such as access to education and infrastructure is significant, it is not perfect [3], this attribute becomes even more important. Furthermore, according to the Poverty and Shared Prosperity Report 2020, the monetary headcount ratio does not account for more than a third of those living in multidimensional poverty. The MPM of a country is at least as high as or higher than monetary poverty, indicating that nonmonetary components play a larger role in multidimensional poverty and are important for overall well-being. Despite abundant natural and human resources, poverty continues to be one of Nigeria's major challenges six years after the SDGs were established. Nigeria continues to have one of the world's greatest populations of poor people, according to available data. According to Nigeria bureau of statistics [13], the majority of Nigerians are impoverished. The rate of multidimensional poverty is rising, according to World Bank data on multidimensional poverty.

A comprehensive approach to poverty research has been employed in several studies in Nigeria, with conflicting results ([2]; [4]; [5]; [6]; [7]). Since the early 2000s, these studies have looked at the extent of multidimensional poverty in Nigeria, its drivers, and decompositions across gender, urban and rural areas, and geographical regions. According to their findings, poverty is endemic in Nigeria, with high and different degrees of multidimensional poverty across geographical regions. The purpose of this study is to find out how common and severe multidimensional poverty is in Nigeria. The purpose is to emphasize the fundamental causes of multidimensional poverty in Nigeria in general, as well as variations between regions and locations of residence in Nigeria, using evidence from the 2018/2019 LSMS data. Previous research have underlined the pervasiveness of multidimensional poverty in northern Nigeria [8], and this study will use data from the 2018/2019 Living Standard Measurement Survey to test this assumption (LSMS). The Alkire Foster (AK) approach will be utilized to assess multidimensional poverty in this study. The AK technique is built on the Sens capapbility principle. Poverty is viewed as a complicated problem with many interwoven variables that interact to obstruct human functioning. According to Sen (14) in Alkire, Foster, Seth, Santos, Roche, and Ballón [1] "the capacity approach is concerned with a multiplicity of varied qualities of our lives and concerns."

\section{Literature review}

Ajakaiye, Afeikhena, Olaniyan, Mahrt and Alaba [2] Used the unique first order dominance approach proposed by Arndt, Distante, Hussain, Osterdal and Ibraimo [9] to assess Nigeria's non-monetary multidimensional poverty. Using comparable datasets, the Nigeria Demographic and Health Surveys of 1999, 2003, and 2008 for national, regional, and zonal analysis, and the Harmonized Nigeria Living Standard Survey of 2008/09 as well as the Nigeria Living Standard Survey of 2003/04 for state analysis, the study looked at five dimensions of deprivation: education, water, sanitation, shelter, and energy. The findings are convincing, confirming the widespread belief that poverty in Nigeria has not kept pace with the country's strong economic progress over the last decade. Only a small increase in non-income poverty was recorded in the country. Between 1999 and 2008, the percentage of the population experiencing acute deprivation decreased by -0.21 , and just one of the variables (sanitation) showed a significant improvement. The bootstrap analysis of spatial first order dominance comparisons shows that regional inequalities persist, with substantial discrepancies in states. The northern section of the country has ten of the lowest-ranking states.

Sulaimon [5] uses 2016 cross-sectional data to assess the drivers of multidimensional poverty in Nigeria. The Multidimensional Poverty Index is a proxy for multidimensional poverty (MPI). Analysis of variance (ANOVA), Tukey's test, and ordinary least squares were used to analyze the data (OLS). The ANOVA results reveal that multidimensional poverty varies significantly among geopolitical regions. The Tukey's test demonstrates significant differences in multidimensional poverty between southern and northern areas, as well as most northern sub-regions. In the south, there are no notable differences in multidimensional poverty amongst sub-regions. After adjusting for capital expenditure, the OLS findings suggest that labor force and fertility rate have substantial influence on multidimensional poverty, with the latter showing a positive association. The research finds that, given Nigeria's vast population, a rise in the fertility rate will result in a massive increase in the multidimensionally poor population.

Ologbon, Idowu, Salmonu and Oluwatayo [10] looked at the level of multidimensional deprivation and poverty among households in south western Nigeria's riverine districts. 448 riverine families in South-Western Nigeria provided data for this study. Only around 16 percent of the households had members gainfully employed, while approximately 68 percent of the household heads engaged in onshore livelihood activities. The average household size was 5, with fiftysix percent (56\%) having less than nine years of obligatory and basic education. The majority (60.3 percent) of the households were deprived in eight indicators (61.54 percent of the total potential number of deprivations) or more, with all $(100 \%)$ of the riverine households being classified as poor in around $6 \%, 12 \%$, and $19 \%$ of the thirteen dimensions of deprivation, respectively. The adjusted multidimensional poverty rate of the families (M0 $=0.3422)$, adjusted poverty gap $(M 1=0.1608)$, and poverty severity $(M 2=0.0761)$ at the dual cutoff value $(k=8)$ revealed a high 
level of inequality among the poor. Finally, poverty was manifested in the riverine households' basic standard of living commodities and services, as evidenced by their low level of education, restricted access to sanitary sources of drinking water, food, energy, health care, toilet facilities, and better means of livelihood.

Adepoju [4] Used the Alkire and Foster Measure of Multidimensional Poverty, the Markov Model of Poverty Transitions, and the Multinomial Logistic Regression Model to analyze multidimensional poverty transitions in rural Nigeria. The findings revealed that multidimensional poverty is primarily chronic (46.5 percent) among Nigerian rural households, with education and assets aspects contributing the most to the prevalence and severity of multidimensional poverty among the households. Transient poverty was influenced by educational status, household size, number of assets owned, and land ownership, whereas chronic poverty was influenced by marital status, household size, land ownership, and number of assets possessed. The report suggests that necessary regulations be enacted and implemented to combat rural women's marginalization in asset ownership, as well as increased efforts and incentives to encourage human capital development in rural areas.

Alemu [8]. measured the amount of poverty in Nigeria and its distribution across zones and states using a multidimensional approach. The study looked at how well-being indicators affect average poverty and provides a tool to help with project planning at various phases. The following are the findings of the study: (i) Nigeria's poverty rate is high, averaging 52 percent, regardless of whether poverty is measured by income or a combination of income and nonincome elements. This could be explained by the structure of growth and the lack of spending policies that benefit the poor. (ii) The majority of Nigeria's poverty is concentrated in three geopolitical zones in the north: the North East, North West, and North Central. (iii) Variations in service delivery could explain higher average impoverishment in some states. (iv)In education, housing, energy, and bathroom facilities, state-level disparities in average deprivation are the highest. Conversely, average deprivation is the highest, while variances in employment, income, sanitation, and access to water are the smallest across states. As a result, a combination of state and federal poverty-reduction strategies will be required. (v) Households place a higher value on education, energy, and employment, meaning that investments in these areas could help Nigerians live better lives.

Ifelunini, Jonah, Wosowei and Otene [6]. used the Core Welfare Indicator Questionnaire (CWIQ) Data, a non-monetary welfare indicator survey, to conduct an analysis of multidimensional poverty incidence in Nigeria. The study employed a sample of 77,400 (seventy-seven thousand, four hundred) dwelling units from 36 states and the Federal Capital Territory FCT. Housing, Education, Energy, Health, and Land Access were created as non-monetary welfare indicators for the study. The data was analyzed using Principal Component Analysis (PCA) and Adapted-Foster Greer and Thorbecke. The non-monetary poverty line was calculated using the PCA. In each of the poverty groups, a Kaiser-MeyerOlkin model adequacy value of 0.75 was found. The study found that poverty in Nigeria has no geographical boundaries, with high rates of multidimensional poverty in all geopolitical zones/groupings. The following recommendations were made: the government should target specific regions or states based on the poverty attributes from which they suffer the most; the government should include other poverty attributes in their poverty eradication programs rather than focusing solely on moving people out of a certain income poverty level.

Adetola and Olufemi [11]. The Demographic and Health Survey, 2008 data was used to create profiles of the factors of child poverty in rural Nigeria. The notion of multidimensional child poverty was applied to children under the age of five. A total of 4,543 children were studied in total. About half of the youngsters were male, and the average age of the entire group was 29 months. To create weights for the five variables utilized in the multidimensional poverty calculations, a single step Multiple Correspondence Analysis (MCA) was used. Safe drinking water, sanitation, housing, health, and nutrition are the five dimensions. To create multidimensional poverty profiles for the children, the [1] counting method was used. When the poverty cutoff was set at $K=1,52$ percent of the children were multidimensionally poor, compared to $27.9 \%$ when $\mathrm{k}=3$. This means that 52 percent of children are multidimensionally impoverished when they are deprived in at least one area. The health and sanitation categories contributed the most to the overall multidimensional poverty index, with 38.54 percent and 22.58 percent, respectively.

Usman [12]. used the latest method proposed by [1] to calculate the multidimensional poverty index (MPI) of rice farming households in Nigeria's northern region. The study's data were gathered from 199 rice farmers in Nigeria's three primary rice producing systems using a multistage sampling approach. The study looked at ten variables from three key areas of well-being: health, education, and standard of life. The research was conducted using the STATA command 'MPI,' which facilitates the collection of deprivation indicators for rice farming households into policy domains. According to the findings, almost 82 percent of rice farming households live in poverty. Lowland rice farming households had the most multidimensional poverty, followed by highland, and then irrigated rice farming households, according to disaggregated results by rice farming systems subgroups. Three significant indicators contributing to multidimensional poverty among households were identified to be access to general hospitals, nutrition, and children's 
enrollment in school. In the rice farming systems, the youngsters under the age of 46 were the most multi-dimensionally poor farmers. As a result, anti-poverty measures that improve households' access to health and education indicators, with a particular focus on youth, are more likely to alleviate poverty among rice farmers. Liberating rice farmers from the multiple hardships they are facing could go a long way toward realizing Nigeria's accelerated rice self-sufficiency.

Orji, Ogbuabor, Nwosu, Anthony and Amoji [7] investigated the prevalence of multi-dimensional poverty in South East Nigeria and its determinants. The study used the Alkire-Foster approach and the logit model to discover that income (less than minimum wage), education, and consumption are all significant predictors of poverty and deprivation across dimensions. The findings revealed that, based on per capita consumer expenditure, almost $60 \%$ of the population in the South East lives on less than $\$ 1.25$ per day. Those without formal education are poorer than those with formal education, according to the pattern of group-specific poverty headcounts. Seventy percent of residents in rural areas were determined to be impoverished, compared to thirty percent in metropolitan areas. Based on poverty headcounts, maleheaded households were shown to be significantly poorer than female-headed households; nevertheless, female-headed households are more disadvantaged than male-headed households in multi-dimensional poverty headcounts. The findings also revealed that being a female-headed household in rural areas with a big household size exacerbates multidimensional poverty. All of these factors were discovered to raise the risk of being multi-dimensionally poor. A household with electricity also has a lower incidence of multi-dimensional poverty, according to the findings. As a result, the study advised that the government give more attention to female-headed households and rural areas by providing basic utilities to help them improve their socioeconomic conditions. Because the availability of electricity and other infrastructure decreases poverty, the government should make power (electricity) and other infrastructure provision a top priority.

\section{Methodology}

\subsection{The Alkire Foster methodology}

The AF technique of multidimensional poverty measuring is a set of measures that draws on the counting approach while also naturally expanding the FGT set of measures. Subgroup decomposition, dimensional breakdown, and dimensional monotonicity are three fundamental aspects of the AF technique. There are two steps to the AF technique. Identification is the initial phase, followed by Aggregation. The person is used as a unit of identification in this investigation. The Alkire-foster methodology computes two key statistics for ordinal data:

- The headcount ratio of multidimensional poverty $\mathrm{H}$, also called the incidence of multidimensional poverty: it measures the proportion of people (within a given population) who experience multidimensional poverty. This is also called the 'multidimensional headcount ratio' or simply the 'headcount ratio'. Sometimes it is called the 'rate' or 'incidence' of poverty. It is the number of poor people q over the total population $\mathrm{n}$.

- $H=\frac{q}{n}$

- The adjusted headcount ratio Mo: It measures the proportion of deprivations that poor people in a society experience, as a share of the deprivations that would be experienced if all persons were poor and deprived in all dimensions of poverty. It is the product of two intuitive partial indices, the Incidence and Intensity of Poverty $(\mathrm{H} \times \mathrm{A})$.

$$
M o=H A=\frac{1}{n} \sum_{i=1}^{n} c(k)=\frac{1}{n} \sum_{i=1}^{n} \sum_{j=1}^{d} w_{j} g_{i j}^{0}()
$$

This study will decompose multidimensional data across Nigerian regions. The goal is to determine the severity of multidimensional poverty in these subgroups, as well as the subgroups' contribution to overall poverty and the key predictor of multidimensional poverty in these subgroups. All AF metrics can be broken down into subgroups and deconstructed to demonstrate which dimensional deprivations the most important contributors to poverty for any are given group. The second crucial attribute, post-identification dimensional breakdown, is not included in the normal headcount ratio and is very useful for policy. The AF measures also meet dimensional monotonicity, which means that poverty diminishes when a poor person is no longer deprived in a dimension [1]. 


\section{Results}

Table 1 Break down of Dimension and Indicators

\begin{tabular}{|l|l|c|l|}
\hline Dimension & Indicator & Weight & Deprivation Cutoff \\
\hline Consumption & $\begin{array}{l}\text { Per capita consumption } \\
\text { Expenditure }\end{array}$ & $1 / 4$ & $\begin{array}{l}\text { Percapita consumption is less than 137,430 per annum } \\
\text { after adjustment for differences in regions and price }\end{array}$ \\
\hline Education & Schooling (Sc) & $1 / 4$ & Individual has atleast a primary school leaving certificate. \\
\hline Energy/power & Electricity/ Generator & $1 / 4$ & $\begin{array}{l}\text { A household without access to main government electricity } \\
\text { or a generator is assumed to be energy-power deprived. }\end{array}$ \\
\hline Housing & Flooring & $1 / 12$ & The household has a dirt, sand, dung or mud floor. \\
\hline & Crowding & $1 / 12$ & $\begin{array}{l}\text { The house is deemed to be crowded if more than 3 people } \\
\text { per room }\end{array}$ \\
\hline & Toilet & $1 / 12$ & If household members defecate outside \\
\hline
\end{tabular}

Table 2 Descriptive statistics

\begin{tabular}{|c|c|c|c|}
\hline Households & $\begin{array}{l}\text { North } \\
\text { central }\end{array}$ & 4,197 & \\
\hline & North East & 3,526 & \\
\hline & North West & 4,196 & \\
\hline & South East & 3,000 & \\
\hline & South West & 3,597 & \\
\hline & South South & 3,594 & \\
\hline Total number of Households & & & 22,110 \\
\hline $\begin{array}{l}\text { Percentage of household that are deprived in Consumption (Below } \\
137,430 \text { Naira percapita annually) }\end{array}$ & & & $36.174 \%$ \\
\hline Percentage of household that are deprived in education & & & $35 \%$ \\
\hline Percentage of household that are deprived in Energy & & & $45.002 \%$ \\
\hline Percentage of household that live in crowded apartments & & & $17.526 \%$ \\
\hline Percentage of household that live in apartments with inadequate flooring & & & $25.387 \%$ \\
\hline Percentage of household that live in apartments without toilet & & & $30.674 \%$ \\
\hline
\end{tabular}

Source: Nigeria Living standard measurement survey (LSMS) 2018/2019

\subsection{Discussion of Findings}

Table 3 Household Multidimensional Poverty Indices

\begin{tabular}{|c|c|c|c|}
\hline K & MO & H & A \\
\hline 1 & 0.343 & 0.645 & 0.532 \\
\hline 2 & 0.261 & 0.380 & 0.687 \\
\hline 3 & 0.216 & 0.253 & 0.852 \\
\hline
\end{tabular}


The deprivation cutoff $(\mathrm{k})$ represents the number of dimensional deprivation a household must suffer before it can be categorized as multidimensionally poor. With $\mathrm{k}=1$, a household is considered as multidimensionally poor if he is deprived in any of the four dimensions that was used to compute the MPI in this study. With k=2, only households deprived in any two dimensions are classified as multidimensiomally poor and so on.

Evidence from table 3 above indicate that as the deprivation cut off (k) increases from 1 to 3, the Adjusted headcount ratio (Mo) and the headcount ratio $(\mathrm{H})$ declines while the intensity of poverty rises. This is in line with the findings of Adetola et.al [11].

When $\mathrm{k}=1$ the multidimensional poverty index (Mo) is 0.343 and the head count ratio is 0.645 . The value of the headcount ratio indicates that the proportion of people who are poor and deprived in one dimension is about $64 \%$. At this point, the intensity of poverty (A) is about 0.532 . At $\mathrm{k}=2$, the multidimensional poverty index decreases to 0.261 and the proportion of people who are multidimensionally poor and deprived in two dimensions declines to $38 \%$. The intensity of multidimensional poverty is $67 \%$. When $\mathrm{k}=3$ both the Mo and the headcount ratio falls to 0.216 and 0.253 respectively. The poverty intensity rises further to about 0.852 .

Table 4 Contribution of each indicator to MPI at $\mathrm{k}=2$

\begin{tabular}{|l|c|}
\hline Indicator & \% Contribution \\
\hline Consumption & 28 \\
\hline Education & 25.7 \\
\hline Energy & 31.7 \\
\hline Crowding & 3.0 \\
\hline Flooring & 6.0 \\
\hline Toilet & 5.0 \\
\hline
\end{tabular}

\subsection{Authors computations using Stata 16. Data from LSMS 2018/2019}

Evidence from the table 4 indicate that Energy deprivation is the biggest contributor to multidimensional poverty in Nigeria in the period under consideration. It contributes about $32 \%$ to overall multidimensional poverty index. Deprivations in consumption and education respectively contributes $28 \%$ and $25.7 \%$ to overall multidimensional poverty index. This is followed by housing indicators like flooring, toilet and crowding which contributes $6 \%$, 5\% and $3 \%$ respectively.

Table 5 Regional decomposition of Household Multidimensional Poverty Indices at k=2

\begin{tabular}{|l|c|c|c|c|c|c|}
\hline & North Central & North East & North West & South East & South South & South West \\
\hline H & $16.7 \%$ & $28.7 \%$ & $33 \%$ & $9.6 \%$ & $6.6 \%$ & $4.5 \%$ \\
\hline MO & $16.3 \%$ & $29.1 \%$ & $35 \%$ & $9.4 \%$ & $6.1 \%$ & $4.2 \% \%$ \\
\hline
\end{tabular}

Information from the table 5 clearly shows that the North East and the North West contributes the greatest proportion to both multidimensional poverty index (Mo) and the headcount ratio $(\mathrm{H})$. This is closely followed by the North central geographical region in Nigeria. This finding is in line with the work of Alemu [8], who found similar evidence.

The percentage contribution of the North West, North East and North Central to the overall poverty headcount in Nigeria is 33\%, 29\% and $17 \%$ respectively. The southwest and South South has the lowest poverty incidence in Nigeria in the period under review with $4.5 \%$ and $6.6 \%$ followed closely by the South East geographical region in Nigeria with 9.6.

In terms of the adjusted headcount ratio, the same pattern repeats itself with the North West and North East accounting for the largest chunk of people that are multidimensional poor. Numerically, the contribution of the North West and North East to the overall multidimensional poverty index is 35\% and 29\% respectively. The north central accounts for about $16 \%$ of overall MPI. Similar to the poverty headcount ratio, the South west and South South has the lowest 
contribution to multidimensional poverty index in Nigeria. They account for only $4.2 \%$ and $6.1 \%$ of overall multidimensional poverty in Nigeria.

Table 6 Contribution of Each Dimension to Multidimensional Poverty Index

\begin{tabular}{|l|c|c|c|c|c|c|}
\hline & North central & North East & North West & South East & South South & South West \\
\hline Consumption & 0.298 & 0.303 & 0.279 & 0.324 & 0.253 & 0.176 \\
\hline Education & 0.217 & 0.218 & 0.305 & 0.240 & 0.266 & 0.285 \\
\hline Energy & 0.326 & 0.331 & 0.305 & 0.278 & 0.339 & 0.331 \\
\hline Housing & 0.159 & 0.148 & 0.111 & 0.158 & 0.143 & 0.208 \\
\hline
\end{tabular}

Source: Authors computation using Stata 16. Data from LSMS 2018/2019

Deprivation in Energy is the single most important contributor to multidimensional poverty across all geographical regions in Nigeria. It contributes between $27 \%$ and $34 \%$ of overall multidimensional poverty in different geographical regions in Nigeria. This is followed closely by deprivations in Education and Consumption. Deprivation in Housing contributes the least to multidimensional poverty.

\section{Conclusion}

Interest has switched from unidimensional poverty measurements to multidimensional poverty measures that represent the plural nature of poverty as the world community has come to understand the multiple nature of poverty. In light of new data, this study aims to comprehend the nature of multidimensional poverty in Nigeria. The study used data from the Nigerian LSMS 2018/2019 to estimate the overall MPI for Nigeria, which included six indices of deprivation from four dimensions: consumption, education, energy, and housing. The study also performed a decomposition of multidimensional poverty across Nigerian regions, as well as a dimensional breakdown of multidimensional poverty across Nigeria and across regions. According to the study, Nigeria has a high rate of multidimensional poverty, with around $64 \%$ of the population living in poverty in at least one of the four categories studied. The North West, North East, and North Central, on the other hand, account for the majority of Nigeria's multidimensional poverty, accounting for more than $70 \%$ of the country's overall multidimensional poverty. The South West has the lowest poverty rate, followed by the South South and the South East. Deprivations in education, energy use, and housing, according to the report, are the three biggest contributors to MPI.

\section{Recommendations}

The study revealed a number of interesting results which have policy implications; hence it is recommended that:

- Programs and policies aimed at reducing poverty should take into account the nature and distribution of multidimensional poverty in Nigeria. Policies must be holistic in nature and must be aimed at targeted groups so as to reach the poorest of the poor .Furthermore, policies aimed at reducing poverty in Northern Nigeria will go a long way in reducing overall multidimensional poverty in Nigeria.

- Energy poverty is closely linked and interrelated with other deprivations that compound multidimensional poverty. There is a need for improvement in the supply and distribution of electricity across households in Nigeria. This will go a long way in improving access to energy and reducing energy deprivations and other associated deprivations.

Deprivations in education was identified as one of the biggest contributor to overall multidimensional poverty across all geographical region in Nigeria. Consequently, there is a need for increased investment in Education so as to ensure that every individual has access to basic education. This will go a long way in reducing overall multidimensional poverty as well as ensure the achievement of the Sustainable development Goals.

\section{Compliance with ethical standards}

\section{Acknowledgments}

The authors would like to express their gratitude to all those who must have contributed in one way or the other to the execution of this study. 


\section{Disclosure of conflict of interest}

The authors declare no potential conflicts of interest with respect to the research, authorship, and or publication of this article.

\section{References}

[1] Alkire S, Foster J, Seth S, Santos EM, Roche MJ, Ballón. P. Multidimensional Poverty Measurement and Analysis. Oxford University Press. 2015.

[2] Ajakaiye 0, Afeikhena TJ, Olaniyan 0, Mahrt K, Alaba AO. Multidimensional poverty in Nigeria: First order dominance approach. WIDER Working Paper. 2014/143.

[3] World Bank. World development indicators. Retrieved from: https://www.worldbank.org. 2021.

[4] Adepoju A. Determinants of multidimensional poverty transitions among rural households in Nigeria. International conference of Agricultural Economists. 2018.

[5] Sulaimon MD. Multidimensional poverty and its determinants: Empirical evidence from Nigeria. Munich Personal RePEc Archive. 2020.

[6] Ifelunini A, Jonah AT, Wosowei CE, Otene S. Multidimensional Poverty Incidence in Nigeria: Empirical Insight from Core Welfare Indicator Questionnaire (CWIQ) Survey Innocent .Journal of Economics and Sustainable Development www.iiste.org ISSN 2222-1700 (Paper) ISSN 2222-2855 (Online). 2013; 4(16).

[7] Orji A, Ogbuabor J, Nwosu E, Anthony 0, Amoji N. Analysis of Poverty Correlates and Multi-Dimensionality in South East Nigeria: New Empirical Evidence From Survey Data. Poverty \& Public Policy. 2020; 12: 255-270.

[8] Alemu ZG. Poverty in Nigeria: A Multidimensional Approach, AfDB Working Paper No. 327. Abidjan, Côte d'Ivoire: African Development Bank. 2019.

[9] Arndt CR, Distante MA, Hussain LP, Osterdal PH, Ibraimo M. 'Ordinal Welfare Comparisons with Multiple Discrete Indicators: A First Order Dominance Approach and Application to Child Poverty'. World Development. 2012; 40(11): 2290-301.

[10] Ologbon OAC, Idowu AO, Salmonu K, Oluwatayo IB. Incidence of Multidimensional Poverty among Riverine Households in Southwestern Nigeria .Journal of Agricultural Science. 2014; 6(5).

[11] Adetola A, Olufemi P. Determinants of Child Poverty in Rural Nigeria: A Multidimensional Approach. Global Journal of HUMAN SOCIAL SCIENCE Arts \& Humanities. 2013; 12(12): 1.0

[12] Usman S. Multidimensional Poverty Index of Rice Farming Households in Northern Nigeria: Estimation and Policy Implications. Nigerian Journal of Agricultural Extension. 1 March 2018; 19.

[13] Nigerian Bureau of statistics. Nigeria living standard measurement survey (LSMS). 2018/2019. 2020.

[14] Sen AK.The Idea of Justice. Cambridge MA: The Belknap Press of Harvard University Press. (2009) 